\title{
A Student Led Investigation of the Landscape Dynamics of Campus Recycling
}

\author{
Brandon C. McBride ${ }^{1}$, Cheryl L. Scott ${ }^{1}$, David L. Kulhavy ${ }^{1}$, I-Kuai Hung ${ }^{1} \&$ Daniel R. Unger ${ }^{1}$ \\ ${ }^{1}$ Arthur Temple College of Forestry and Agriculture, Stephen F. Austin State University, Nacogdoches, Texas, \\ USA
}

Correspondence: Daniel R Unger, Arthur Temple College of Forestry and Agriculture, Stephen F. Austin State University, Nacogdoches, Texas, 75962, USA. Tel: 1-936-468-2234. E-mail: unger@sfasu.edu

Received: December 15, 2018

Accepted: December 28, 2018 Online Published: January 19, 2018

doi:10.5539/hes.v9n1p110

URL: https://doi.org/10.5539/hes.v9n1p110

\begin{abstract}
Two senior undergraduate students within the environmental science division at Stephen F. Austin State University (SFASU) quantitatively diagnosed the environmental, ecological, and socioeconomic dynamics involved in plastic recycling. This study incorporated actively collecting recycled plastic bottles on campus to produce an enumerated analysis of recycling on campus; and to gain an understanding of the socioeconomics of recycling via an anonymous survey used to determine the recycling knowledgebase of natural resource students at SFASU. Undergraduate students, via their incorporation into a campus wide environmental site assessment of recycling plastic bottles, were able to apply their classroom knowledge to a real-world environmental concern thus making them more well-rounded and society-ready environmental scientists.
\end{abstract}

Keywords: university, conservation, natural resources, plastic bottles

\section{Introduction}

Undergraduate students completing a Bachelor of Science degree in Environmental Science in the Arthur Temple College of Forestry and Agriculture (ATCOFA) at Stephen F. Austin State University (SFASU), Nacogdoches, Texas, USA, invest themselves in a curriculum that provides students with real-world knowledge on a variety of scientific disciplines that accompany the natural resources. ATCOFA's mission statement is to maintain excellence in teaching, research, and outreach to enhance the health and vitality of the environment through sustainable management, conservation and protection of our forest and natural resources (Bullard, Coble, Coble, Darville, \& Stephens-Williams, 2014). The nationally ranked division of environmental science within ATCOFA prepares students academically and socially providing students with the ability to reason, think critically, and logically address problems they will encounter upon graduation such as the need to address the recycling of natural resources.

It is important to understand the dynamic interactions between people on-campus and recycle bins because social views are often the driving force for economic and ecological action. Therefore, discovering the opinions of students and faculty could assist in finding new possible locations for recycle bins within campus patches and corridors, removing certain bins, and creating educational awareness on-campus. In addition, observation of the corridors people travel from location to location could contribute in deciding the location of these items. Finally, the implementation of surveys and observations of population density on-campus may provide data that could lead to an understanding of this dynamic.

\subsection{Historical Context}

Examining the historical context of a society that has for the majority adopted a "Think Globally, Plan Regionally, Act Locally" approach to the recycling of plastic goods, one can begin to understand the importance and implications that non-recycled materials have on an environment (Forman, 1995). Further, examining new historical evidence that far predates the succession of modern science reveals a phenomenon of recycling from the earliest known forms of human life (Dockterman, 2013).

Due to an expanse in economic structure and resource availability within the last one-hundred years, many developed nations have come to accept that it is simpler and more economical to create new materials rather than to reuse them. These factors contribute to the ever-growing concern for plastic bottle recycling due to the 
complex and time consuming processes that are required to produce plastic. Fournier (2005) reported that 83 percent of colleges surveyed recycled plastic bottles while Mason (2017) points out that university and college recycling programs create a sustainable future by reducing materials used in the production of plastic bottles. Reasons for not recycling included cutbacks in funding, change in the recycle market, and little interest in recycle programs. Positive campus factors promoting recycling included improved public image, and financial savings from recycling and waste management.

\subsection{RecycleMania}

RecycleMania is a competition between universities to collect the largest amount of recyclables from residence halls and dining areas over a ten week period (Pittman, 2012). RecycleMania began in 2001 as a competition between Ohio University and Miami University to motivate students to become better at recycling. It has since grown substantially travelling by word of mouth form university to university. RecycleMania continues to grow in popularity and since its beginning in 2001 has grown to include over 1,000 colleges and universities across the United States and Canada. In 2017, 320 colleges and universities and 4.1 million students participated in RecycleMania with 69.9 million pounds of recyclables and food organics collected.

Since its conception, RecycleMania has gained support from students to collect, measure, and record collected recyclables across college and university campuses. Measurements are reported in pounds (or ounces) of recycled material per student. The lack of staff on any campus to weigh and transport materials has made it unattractive to recycle plastic bottles (Fournier, 2005). In 2008, Aramark worldwide concessionaires challenged college campuses to recycle with RecycleMania (Wysong, Trosien, \& Hancock, 2008). St. John's University has promoted a sustainability initiative incorporating RecycleMania on their campus (Pellow \& Anand, 2009) while Ecker and Yang (2017) promoted reformatting of RecycleMania efforts to increase awareness and decrease campus waste. One drawback of plastic bottles is the time to collect and process for recycling. To successfully recycle, the practice needs to be integrated into daily operations.

\subsection{Integration with Landscape Ecology Components}

Landscape ecological components and applications have numerous implications for the structure, function, change, and management of a resource or habitat of an area (Forman, 1995; Coulson \& Tchakerian, 2010). One of the primary focuses of this particular study was to relate landscape patches, corridors, matrices, and ecotones to the role and effectiveness of recycling on the SFASU campus to promote urban sustainability and well-being of the population $(\mathrm{Wu}, 2008)$. The relationship that these factors have on whether or not a plastic bottle is dispensed in its proper receptacle may entertain the notion of revision of specific areas on campus. In other words, from a landscape ecological perspective, are these factors essential in determining if a person has the capabilities or initiative to recycle a plastic bottle? Answering this fundamental question will involve understanding the ecological significance of the numerous aspects of a landscape.

Another factor on the efficacy of plastic bottle recycling related to landscape ecological principles is the size, shape, number, and location of landscape corridors on campus. A corridor is any feature or pathway that is isolated from the matrix, in this case, the pathway a resource travels from source to sink. These corridors are effective in diagnosing the most lucrative locations for a plastic bottle receptacle. Although there are numerous receptacles on the SFASU campus already, understanding the correlation between the most and least travelled corridors and if the comparative use of these receptacles due to population density of each corridor is an important factor.

\subsection{Study Objectives}

The primary objective of this study was to measure the numbers and weights of plastic bottles recycled at SFASU. The second objective was to evaluate a survey of knowledge of recycling of plastic bottles. The information will be used to increase both recycling and recycling efficiency at SFASU.

\section{Methods}

During the fall 2015 and spring 2016 semesters at SFASU plastic bottles were collected biweekly by The Environmental Awareness Movement (T.E.A.M.) which is an environmental awareness student organization on campus. The goal of T.E.A.M. is to make students more aware of the impact that individual has on the environment and what can be done to reduce our carbon footprint, in order to improve the world for future generations. The focus of T.E.A.M. is to provide opportunities for students whereby they will gain environmental leadership experience by volunteering with the community and learning how to organize groups to help others.

During the 2015-2016 academic year T.E.A.M. collected plastic bottles from several locations (Figure 1) across the SFASU campus and stored all the recyclables in a storage shed located near the football stadium. At this 
location, T.E.A.M. members and volunteers counted and sorted the plastic bottles by type of plastic and volume (ounces) for each location for both RecycleMania and building recycling, then transported the bottles to the Nacogdoches Public Library to be collected by the county for recycling. During the first week of sorting, eight, sixteen, and twenty ounce bottles of type 1 plastic were weighed in triplicate using an analytical balance for a standard weight for data analysis.

To investigate prior and learned knowledge of plastic bottle recycling, a 50 question survey divided into 10 questions of 5 categories (landscape ecology, economics, socioeconomics, litter, and agencies involved in recycling plastic bottles) was compiled. The survey was administered to current upper division environmental science students $(n=30)$ and forestry students $(n=30)$. An 8 minute PowerPoint covering the recycling of plastic bottles was given, then after an interval, a post-questionnaire was given. The results were analyzed using Statistical Analysis System (SAS) using the Kruskal-Wallace Non-parametric sign rank test with an alpha of $\leq$ 0.05 and Before Environmental, After Environmental, Before Forestry, and After Forestry were compared for significant differences.

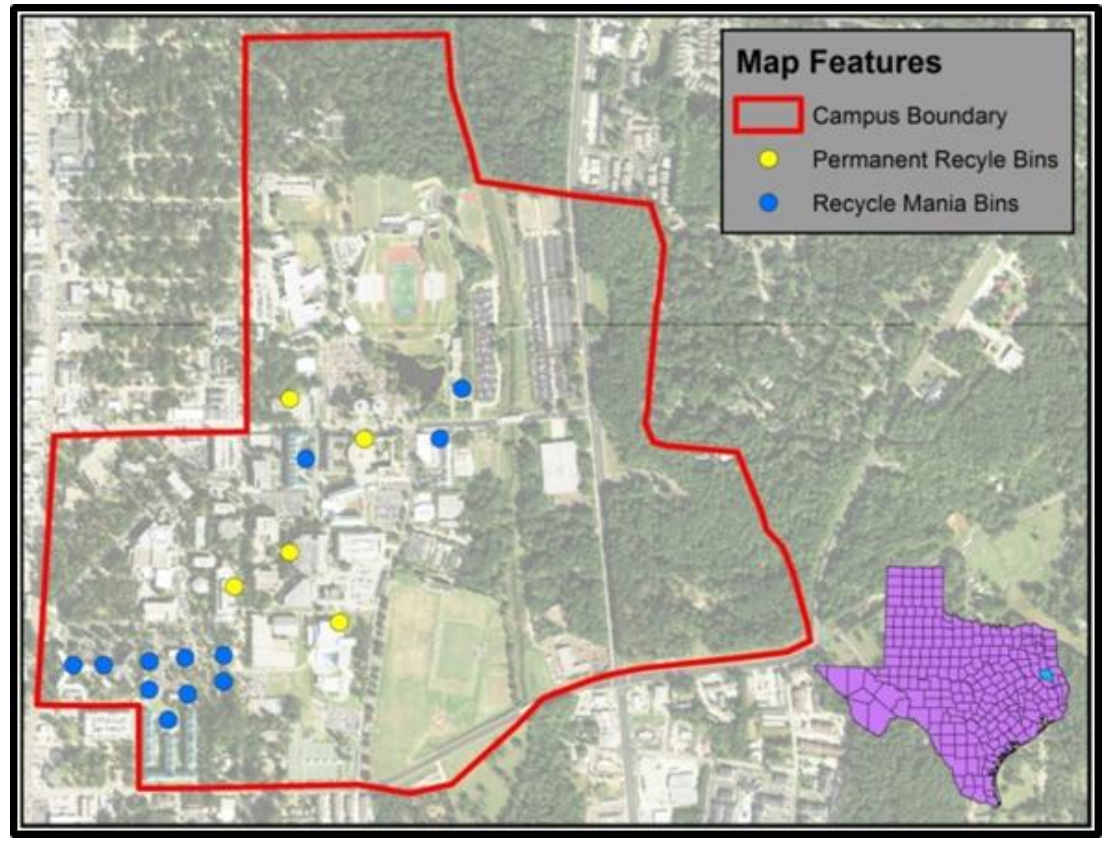

Figure 1. Location of permanent and temporary recycle receptacles at SFASU

\section{Results}

The number of plastic bottles, total number of bags, number of recyclable, and number of non-recyclable plastic bottles collected by T.E.A.M. at SFASU located in Nacogdoches, Texas yielded interesting results from fall of 2015 to spring of 2016 (Table 1). With the addition of RecycleMania in the spring 2016, a competition involving the most prominent university recycling programs in the nation, there was a significant increase in the amount of recyclables collected (Fournier, 2005). Comparing values obtained in Table 2 breaks this information down further into the total counts of plastic bottles for each type of plastic. Consequently, an increase in recyclable plastic (types 1 and 2) was observed in the spring of 2016, whereas the numbers obtained for non-recyclable material decreased.

Further, the total amount of ounces as well as the average amount of ounces per bag for both semesters is displayed in Table 3. Examining the values seen in this table more closely, it was concluded that the volume of 87,287 ounces generated in the fall equates to approximately three and a half times the volume of the average household hot tub which can hold approximately 24,300 ounces of water. Alternatively as seen in the spring in Table 3, the value of 133,986 ounces equates to approximately five and a half times the volume of a hot tub. Therefore, the amount of volume that could be saved in a landfill from plastic bottle recycling on campus alone represents approximately 9 times the volume of a hot tub. Assuming that 7 billion people inhabit the planet and 11,000 students at SFASU, if the world were to recycle at the same rate as SFASU students then it would equate to about three and a half times the volume of the Houston Astrodome every year (The Measure of Things, 2016). 
This value is based on the assumption that every person on the planet generates the same amount of plastic bottle waste as the average college student which is false however; it does implicate the problems that could arise in a future without proper management of plastic resources. The plastic bottles collected for spring 2016 is further broken down by which plastic bottles were collected from permanent recycle receptacles and which were collected due to RecycleMania as seen in Table 4. It is apparent from these values that the addition of programs such as RecycleMania greatly increases the amount of recycling on campus.

Table 1. The number of bags of plastic bottles, plastic bottles, recyclable bottles, and non-recyclable plastic bottles collected by T.E.A.M. at SFASU for fall 2015 and spring 2016

\begin{tabular}{lll}
\hline Item & Fall 2015 & $\begin{array}{c}\text { Count } \\
\text { Spring 2016 }\end{array}$ \\
\hline Bags & 32 & 46 \\
Bottles & 5142 & 7454 \\
Recyclable & 5092 & 7427 \\
Non-recyclable & 50 & 27 \\
\hline
\end{tabular}

Table 2. Number of each type of plastic bottle collected by T.E.A.M. at SFASU for fall 2015 and spring 2016

\begin{tabular}{lll}
\hline Type & Fall 2015 & Spring 2016 \\
\hline 1 & 5063 & 7345 \\
2 & 29 & 82 \\
3 & 0 & 0 \\
4 & 1 & 0 \\
5 & 25 & 20 \\
6 & 23 & 7 \\
7 & 1 & 0 \\
\hline
\end{tabular}

Table 3. The total amount of ounces and average amount of ounces per bag for plastic bottles collected by T.E.A.M. at SFASU for fall 2015 and spring 2016

\begin{tabular}{lll}
\hline & Fall 2015 & Spring 2016 \\
\hline Total Ounces & 87287 & 133986 \\
Average Per Bag & 2728 & 2734 \\
\hline
\end{tabular}

Table 4. Number of plastic bottles and ounces collected by T.E.A.M. at SFASU for spring 2016

\begin{tabular}{lll}
\hline Recycle Type & Bottles & Ounces \\
\hline RecycleMania & 5823 & 106022 \\
Permanent & 1631 & 27964 \\
\hline Total & $\mathbf{7 4 5 4}$ & $\mathbf{1 3 3 9 8 6}$ \\
\hline
\end{tabular}

Further, the number of bottles and ounces that were collected due to RecycleMania can be seen in Tables 5 and 6 . Based on these data, more plastic bottles and ounces were collected in spring 2016 due to the RecycleMania competition. Figure 2 displays the plastic bottles collected for the fall 2015 semester. Finally, weights of an eight, sixteen, and twenty ounce type one plastic are displayed in Table 7. The mean and p-value for each question tested for environmental science $(n=30)$ and forestry students $(n=30)$ are grouped according to the category of landscape ecology, economics, socioeconomic, litter, agencies that recycle as well as the overall scores can be seen in Table 8. Based on these results, there was a significant difference in responses before and after each individual major overall and for each category because p-values were below 0.05 except for the category agencies for forestry students $(\mathrm{p}=0.062)$. Based on these results, each major received adequate knowledge on the topics during the presentation except for the topic of agencies with the forestry students. Further, when comparing each major's results for each category and overall, there was only a significant difference in responses between environmental science and forestry students for landscape ecology after $(p=0.017)$, socioeconomic before $(p=0.015)$, litter before $(p<0.001)$ and after $(p=0.025)$, and agencies before $(p<0.001)$. These results can be inferred that each major did not absorb the information the same way. These results can help determine how to improve the teaching method for this gap between majors. 
Table 5. Number of bottles for each location and month collected by T.E.A.M. at SFASU for spring 2016 for RecycleMania

\begin{tabular}{lllll}
\hline Location & February & $\begin{array}{c}\text { Number of Bottles per Month } \\
\text { March }\end{array}$ & April & Total \\
\hline Lumberjack Landing & 61 & 129 & 0 & $\mathbf{1 9 0}$ \\
Griffin & 112 & 194 & 110 & $\mathbf{4 1 6}$ \\
Lumberjack Lodge & 309 & 386 & 143 & $\mathbf{8 3 8}$ \\
Hall 10 & 212 & 78 & 0 & $\mathbf{2 9 0}$ \\
Hall 14 & 0 & 125 & 165 & $\mathbf{2 9 0}$ \\
Hall 16 & 221 & 149 & 0 & $\mathbf{3 7 0}$ \\
Hall 20 & 0 & 329 & 99 & $\mathbf{4 2 8}$ \\
North Hall & 0 & 384 & 0 & $\mathbf{3 8 4}$ \\
South Hall East & 75 & 131 & 55 & $\mathbf{2 6 1}$ \\
Steen Hall West & 159 & 365 & 0 & $\mathbf{5 2 4}$ \\
Kerr & 189 & 761 & 155 & $\mathbf{1 1 0 5}$ \\
Mays & 0 & 129 & 0 & $\mathbf{1 2 9}$ \\
Todd & 0 & 85 & 224 & $\mathbf{3 0 9}$ \\
Wisley & 0 & 132 & 34 & $\mathbf{1 6 6}$ \\
University Woods & 0 & 123 & 0 & $\mathbf{1 2 3}$ \\
\hline Total & $\mathbf{1 3 3 8}$ & $\mathbf{3 5 0 0}$ & $\mathbf{9 8 5}$ & $\mathbf{5 8 2 3}$ \\
\hline
\end{tabular}

Table 6. The number of ounces for each location and month collected by T.E.A.M. at SFASU for spring 2016 for RecycleMania

\begin{tabular}{lllll}
\hline Location & February & $\begin{array}{c}\text { Number of Ounces per Month } \\
\text { March }\end{array}$ & April & Total \\
\hline Lumberjack Landing & 1102 & 2140 & 0 & $\mathbf{3 2 4 2}$ \\
Griffin & 1968 & 3487 & 3661 & $\mathbf{9 1 1 6}$ \\
Lumberjack Lodge & 3843 & 7058 & 2921 & $\mathbf{1 3 8 2 2}$ \\
Hall 10 & 3638 & 1464 & 0 & $\mathbf{5 1 0 2}$ \\
Hall 14 & 0 & 2121 & 3232 & $\mathbf{5 3 5 3}$ \\
Hall 16 & 3692 & 2704 & 0 & $\mathbf{6 3 9 6}$ \\
Hall 20 & 0 & 5613 & 2398 & $\mathbf{8 0 1 1}$ \\
North Hall & 0 & 7139 & 0 & $\mathbf{7 1 3 9}$ \\
South Hall East & 1254 & 2394 & 1134 & $\mathbf{4 7 8 2}$ \\
Steen Hall West & 2788 & 6537 & 0 & $\mathbf{9 3 2 5}$ \\
Kerr & 3167 & 15336 & 2599 & $\mathbf{2 1 1 0 2}$ \\
Mays & 0 & 2296 & 0 & $\mathbf{2 2 9 6}$ \\
Todd & 0 & 1586 & 3756 & $\mathbf{5 3 4 2}$ \\
Wisley & 0 & 2252 & 670 & $\mathbf{2 9 2 2}$ \\
University Woods & 0 & 2072 & 0 & $\mathbf{2 0 7 2}$ \\
\hline Total & $\mathbf{2 1 4 5 2}$ & $\mathbf{6 4 1 9 9}$ & $\mathbf{2 0 3 7 1}$ & $\mathbf{1 0 6 0 2 2}$ \\
\hline
\end{tabular}




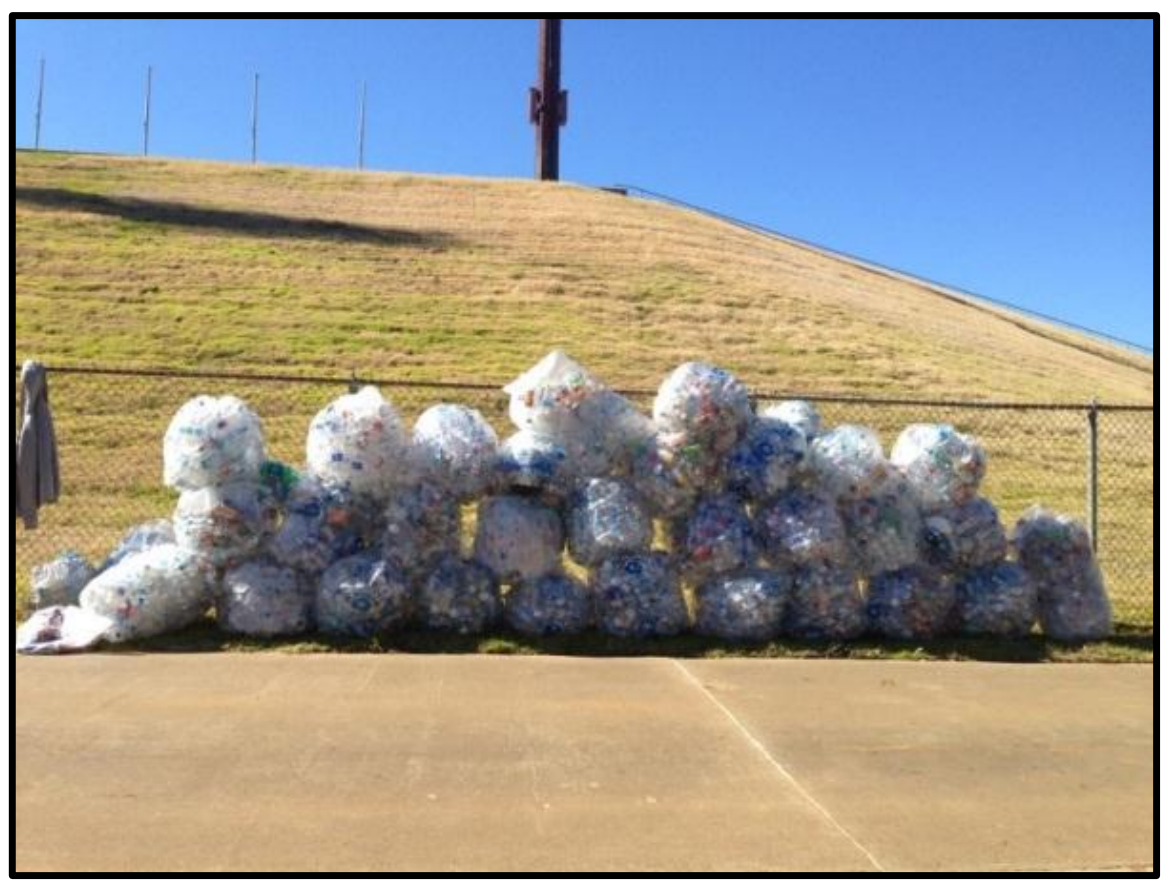

Figure 2. All the plastic bottles collected by T.E.A.M. at SFASU for the fall 2015 semester

Table 7. The weight in grams for an eight, sixteen, and twenty ounce type one plastic bottle collected by weighing one of the plastic bottles collected by T.E.A.M. at SFASU for fall 2015

\begin{tabular}{lr}
\hline Volume (oz) & Weight $(\mathbf{g})$ \\
\hline 8 & 9.93 \\
16 & 11.07 \\
20 & 25.98 \\
\hline
\end{tabular}

Table 8. The mean and p-values for Environmental Science and Forestry students for each survey question category and overall assessment

\begin{tabular}{lllll}
\hline Category & & Before & After & p-value \\
\hline Landscape Ecology & ENV & 4.687 & 5.949 & 0.000 \\
& FOR & 4.547 & 5.717 & 0.000 \\
Economics & p-value & 0.074 & 0.017 & \\
& ENV & 4.138 & 5.276 & 0.000 \\
& FOR & 4.340 & 5.313 & 0.000 \\
Socioeconomic & p-value & 0.379 & 0.861 & \\
& ENV & 3.981 & 4.673 & 0.000 \\
& FOR & 4.373 & 4.900 & 0.000 \\
Litter & p-value & 0.015 & 0.120 & \\
& ENV & 5.465 & 6.314 & 0.000 \\
Agency & FOR & 5.103 & 6.107 & 0.000 \\
& p-value & 0.000 & 0.025 & \\
All & ENV & 4.135 & 4.638 & 0.000 \\
& FOR & 4.650 & 4.753 & 0.062 \\
& p-value & 0.000 & 0.449 & \\
& ENV & 4.811 & 5.370 & 0.000 \\
& FOR & 4.603 & 5.358 & 0.000 \\
\hline
\end{tabular}




\section{Conclusion}

Recycling of plastic bottles at SFASU was based on the principles of landscape ecology to examine the location of material based on the corridors, patches and the forest matrix of the campus. Most material was collected in the campus patches of the residence halls and as a result, recycle bins were located along the corridors that connected the main part of campus and at the building residence halls and the library. Plastic bottles were not as prevalent in the campus forest matrix as there was less use and fewer recycle bins or trash receptacles located in these areas. Both environmental science and forestry students benefitted from information on landscape ecology with an increased knowledge of the structure and function of the campus as it pertained to litter and the subsequent need to recycle. Question and answer sessions were conducted at recycle bin areas on the efforts to maintain a clean campus while participating in the RecycleMania program. The amount of material collected indicates the need to continue to participate in the national recycle competition to both beautify and raise awareness of the college campus.

The purpose of this student led assessment was to quantify recyclable plastic bottles on the SFASU campus in regards to environmental, landscape, ecological, and socioeconomic parameters. In conclusion, approximately $99 \%$ of plastic bottles collected at SFASU are recyclable. These bottles will be transported to the Kilgore recycling plant by Rivers Recycling of Kilgore and Allied Waste to be recycled if the center can hold the capacity. Further, the number of plastic bottles collected at SFASU was greater for spring 2016 when compared to fall 2015. One reason for this is due to the RecycleMania competition that took place. Overall, the students learned from this experience that recycling can be an effective way to preserve natural resources and that by integrating the program on the campus of SFASU they were better able to portray the importance of recycling for the betterment of the greater campus community.

By integrating undergraduate students in a campus wide environmental site assessment, students learned a valuable lesson of applying their educational training within a real-world application. The experience helped make them more well-rounded students and better prepared them to face real-world environmental problems, issues, and concerns upon graduation. In addition, at the end of the project the students involved had a better sense of personal wealth and satisfaction and the importance of working together as a campus community for the well-being of all students on campus. Our approach followed the constructs of R. T. T. Forman (Forman, 1995) of "Think Globally, Plan Regionally, Act Locally" to promote a sustainable environment and reinforced the concept of campus beautification and sense of place while promoting urban sustainability.

\section{References}

Bullard, S., Coble, D., Coble, T., Darville, R., \& Stephens-Williams, P. (2014). Producing 'Society-ready' foresters: A research-based process to revise the Bachelor of Science in Forestry curriculum at Stephen F. Austin State University. Stephen F. Austin State University: ATCOFA Monograph, 1-2014.

Coulson, R. N., \& Tchakerian, M. (2010). Basic Landscape Ecology. College Station, Texas: Knowledge Engineering Laboratory Partners, Inc.

Dockterman, E. (2013). Recycling history: Even cavemen lived a green lifestyle. Time Magazine, Oct. 11, 2013.

Ecker, J. R., \& Yang, K. (2017). Waste management in campus dining-reformatting "RecycleMania" at Central Michigan University. Business Management Dynamics, 7, 1-11.

Forman, R. T. T. (1995). Land Mosaics: The Ecology of Landscapes and Regions. Cambridge, UK: Cambridge University Press.

Fournier, M. R. (2005). Recycle this! A look at recent campus programs. Facilities Manager, January/February, 48-53.

Mason, B. E. (2017). A compressive overview of university and college recycling programs. In A. Kumar \& D. Kim (Eds.), Sustainability Practice and Education (pp. 29-49). University Campuses and Beyond.

Pellow, J. P., \& Anand, B. (2009). The greening of a university. Change: The Magazine of Higher Education, 41, $8-15$.

Pittman, J. S. (2012). Student services and auxiliary enterprises. New Directions for Student Services, 137, 29-30.

The Measure of Things. (2016). Weight: ounce. Retrieved from http://www.bluebulbprojects.com/MeasureOfThings/results.php?comp=weight\&unit=oz\&amt=87286.5

$\mathrm{Wu}$, J. (2008). Making the case for landscape ecology: An effective approach to urban sustainability. Landscape 
Journal, 27, 41-50.

Wysong, S., Trosien, G., \& Hancock, D. (2008). Cheer for the home team... to go green! An explanatory examination of fan's and facility executives' attitudes toward environmentally friendly sports and entertainment venues. Proceedings of the 16th EASM Conference, 235-237.

\section{Copyrights}

Copyright for this article is retained by the author(s), with first publication rights granted to the journal.

This is an open-access article distributed under the terms and conditions of the Creative Commons Attribution license (http://creativecommons.org/licenses/by/4.0/). 